NBER WORKING PAPER SERIES

\title{
THE CONSUMPTION RESPONSE TO PREDICTABLE CHANGES IN DISCRETIONARY INCOME: EVIDENCE FROM THE REPAYMENT OF VEHICLE LOANS
}

\author{
Melvin Stephens Jr. \\ Working Paper 9976 \\ http://www.nber.org/papers/w9976 \\ NATIONAL BUREAU OF ECONOMIC RESEARCH \\ 1050 Massachusetts Avenue \\ Cambridge, MA 02138 \\ September 2003
}

I would like to thank Kerwin Charles, Steve Haider, and seminar participants at the Bureau of Labor Statistics, Carnegie Mellon University, MIT, and the University of Virginia for helpful comments and suggestions. I would also like to thank the staff at the BLS, especially Wolf Weber, for providing answers to numerous data questions as well as access to previously unavailable data. Sujoy Chakravarty provided research assistance. The views expressed herein are those of the authors and are not necessarily those of the National Bureau of Economic Research.

(C)2003 by Melvin Stephens Jr.. All rights reserved. Short sections of text, not to exceed two paragraphs, may be quoted without explicit permission provided that full credit, including $(\mathcal{C}$ notice, is given to the source. 
The Consumption Response to Predictable Changes in Discretionary Income:

Evidence from the Repayment of Vehicle Loans

Melvin Stephens Jr.

NBER Working Paper No. 9976

September 2003

JEL No. D91

\begin{abstract}
Whether households "smooth" consumption in response to predictable changes in income is an open and contentious question. This paper examines the consumption reaction to predictable increases in discretionary income following the final payment of a vehicle loan. Using data from the Consumer Expenditure Survey, the results show that a 10 percent increase in discretionary income due to a loan repayment leads to a 2 to 3.5 percent increase in non-durable consumption. Additional analysis suggests that these findings may be explained by the presence of borrowing constraints.
\end{abstract}

Melvin Stephens Jr.

H. John Heinz School of Public Policy and Management

Carnegie Mellon University

4800 Forbes Avenue

Pittsburgh, PA 15213

and NBER

mstep@cmu.edu 


\section{Introduction}

Whether households "smooth" consumption in response to predictable changes in income is an open and contentious question. The initial strand of the literature using micro data to study this question produced a range of results both in favor of as well as rejecting the Life-Cycle/Permanent Income Hypothesis (LCPIH) (Browning and Lusardi 1996). The high degree of measurement error in consumption data (Shapiro 1984) - exacerbated by the use of consumption changes as the dependent variable in the empirical analysis - is partially responsible for the variation in the estimates across these studies. Predictable income changes, which are typically estimated by the econometrician, may be an even more important reason for the variety of results due the construction of these measures. The lack of powerful instruments when predicting income changes will attenuate the corresponding parameter estimates (Altonji and Siow 1987). Alternatively, the instruments themselves may belong in the consumption equation which will bias the coefficients in favor of rejecting the LCPIH. It is not surprising, then, that this literature is unable to reach a consensus.

A more recent literature tests the LCPIH using exogenous variation in income. Studies of the different seasonal income fluctuations across workers in Thailand (Paxson 1993), the bi-annual income changes in Spain (Browning and Collado 2001), and the annual oil dividend payments to residents of Alaska (Hsieh 2003) fail to reject the hypothesis. Studies of bargained union wage changes (Shea 1995), the variation in income due to the U.S. payroll tax system (Parker 1999), and U.S. income tax refunds (Souleles 1999) all reject the hypothesis. Given the differing outcomes across these (relatively few) studies, a consensus has yet to be reached in this strand of the literature. ${ }^{1}$

This paper examines the consumption response to an increase in household discretionary income due to the repayment of a vehicle loan. Vehicle loans specify a number of payments (or maturity) for repaying the loan at the loan's inception. Upon making the final loan payment, the household's monthly discretionary income will increase. Since the amount and the date of this increase in discretionary income are known to the household well in advance of the loan's repayment, household consumption should not increase when

\footnotetext{
1 Browning and Crossley (2002) suggest that one interpretation of these results is that households are more likely to smooth consumption when the utility losses from not doing so are large.
} 
the vehicle loan is paid off. This observation is the basis of the LCPIH test performed in this paper. $^{2}$

The U.S. Consumer Expenditure Survey (CEX) is used to implement this test of the LCPIH. The CEX surveys households each quarter for four consecutive quarters. For each car loan held by a household, the CEX collects information on the date that the loan payments began, the loan's maturity, and the amount of the monthly payments. This information is used to determine the date and the amount by which the household's discretionary income will increase when the loan is paid off. This study measures the impact of the predictable increase in quarterly household income due to the loan repayment on quarterly household consumption.

This paper finds a significant consumption response to the repayment of vehicle loans. The estimates imply that a 10 percent predictable increase in discretionary income corresponds to a 2 to 3.5 percent increase in non-durable consumption. The results are shown to be robust to a number of sample specifications. The findings also indicate that the consumption increase is permanent rather than a temporary increase in spending following the loan repayment. The impact of liquidity constraints on this excess sensitivity finding is also explored. When defined by age or by wealth, the results are suggestive that borrowing constraints play a role in explaining this response. However, no difference between the response of constrained and unconstrained households is found when loan maturity (i.e., the number of loan payments) is used to proxy for the presence of these constraints. Overall, the results found in this paper provide evidence the household consumption is excessively sensitive to predictable discretionary income changes following a vehicle loan repayment.

The paper is set out as follows. The next section provides a simple model relating the impact of loan repayment on household consumption. The following two sections discuss the data used and the empirical methodology, respectively. The empirical results are then presented and the final section concludes.

2 A small number of related studies examine consumption changes in response to fixed payments. Engelhardt (1996) finds that households increase their consumption following a home purchase which is consistent with liquidity constraints imposed upon these households by the necessity of saving for a mortgage down payment. Souleles (2000) finds that households smooth consumption when college tuition payments are made at the beginning of the fall semester. 


\section{A (Simple) Model of Vehicle Loan Repayment and Consumption}

The literature examining the vehicle purchase decision encompasses a number of theoretical and empirical methodologies. One set of papers estimates (S,s) models of vehicle purchases (Eberly 1994; Attanasio 1995). These papers are concerned with the underlying structural parameters of the purchase decision and abstract from the consumer's method of financing the vehicle purchase. Another set of papers uses an Euler Equation framework to examine vehicle purchases with a focus on the role of liquidity constraints (Chah, Ramey, and Starr 1995; Alessie, Devereux, and Weber 1997). Although this set of papers explicitly incorporates the fraction of the vehicle that may be financed to demonstrate how liquidity constraints may affect the timing of vehicle purchases, they do not examine the subsequent relationship between loan payments and consumption behavior. One paper that explicitly models the repayment of vehicle loans is by Attanasio, Goldberg, and Kyriazidou (2000) who do so within the context of a life-cycle model. The emphasis in their paper is on the relationship between interest rates, borrowing constraints, and the features of the loan chosen at the time of purchase. As such, although they derive the consumer's Euler Equation during the loan period, they do not examine consumption behavior upon the final repayment of the loan.

The impact of the final loan payment on household consumption can be illustrated using the Attanasio, Goldberg, and Kyriazidou model. This three-period model assumes that that there is no uncertainty and that non-durable consumption is both intertemporally separable and separable from vehicle consumption. Relative prices of non-durables and vehicles are fixed at one and there is no depreciation on the vehicle. Vehicles can only be purchased in the first period, cannot be resold, and the loan must be re-paid in its entirety in the second period. Consumers can only borrow to finance the vehicle purchase and can finance a fraction $\phi$ of the vehicle's value where $0 \leq \phi \leq 1$. Consumers are allowed to save

in an asset although this asset cannot be negative. The interest rate on this asset, $r^{l}$, is assumed to be less than the interest rate for financing the vehicle, $r^{b}$.

For the consumer's problem, $C_{t}$ is non-durable consumption for periods $t=1,2,3, y_{t}$ is income in period $t$, and $K$ is the value of the vehicle. The vehicle loan, which is valued at $\phi K$, must be repaid in period two which means the loan payment is $\phi K\left(1+r^{b}\right)$. Allowing 
$\beta$ to be the discount rate, the consumer's problem is

$$
\max _{C_{1}, C_{2}, C_{3}, K, \phi} U\left(C_{1}\right)+\beta U\left(C_{2}\right)+\beta^{2} U\left(C_{3}\right)+V(K)
$$

subject to the inequality constraints

$$
\begin{gathered}
C_{1}+K(1-\phi) \leq y_{1} \\
C_{2}+\phi K\left(1+r^{b}\right)-\left(1+r^{l}\right)\left(y_{1}-C_{1}-K(1-\phi)\right) \leq y_{2} \\
C_{3}-\left(1+r^{l}\right)\left[y_{2}-C_{2}-\phi K\left(1+r^{b}\right)+\left(1+r^{l}\right)\left(y_{1}-C_{1}-K(1-\phi)\right)\right] \leq y_{3} \\
\phi \leq 1 \\
-\phi \leq 0
\end{gathered}
$$

These constraints have corresponding Kuhn-Tucker multipliers $\lambda_{k} \geq 0, k=1,2,3,4,5$.

It is straightforward to derive the Euler Equations linking non-durable consumption between the second (loan repayment) and third periods. ${ }^{3}$ If assets are non-zero at the end of period two then the standard Euler Equation holds

$$
U_{C 2}=\beta\left(1+r^{l}\right) U_{C 3}
$$

where $U_{C t}$ is the marginal utility of non-durable consumption in period $t$. According to equation (6), changes in the marginal utility of non-durable consumption at the time of loan repayment should not depend upon the magnitude of the loan payment. However, if end of period two assets equal zero then the Euler Equation becomes

$$
U_{C 2}=\lambda_{2} / \beta+\beta\left(1+r^{l}\right) U_{C 3}
$$

The latter result is equivalent to the Zeldes (1989) Euler Equation when the consumer is borrowing constrained. The marginal utility of consumption will be greater in period two than in period three if households are unable to borrow in order to "consumption

\footnotetext{
3 Attanasio, Goldberg, and Kyriazidou derive the Euler Equations linking consumption between the first two periods in their paper. The detailed derivation of the Euler Equations linking consumption in periods two and three is available from the author.
} 
smooth". For these constrained households, increases in discretionary income following the loan repayment will lead to increases in non-durable consumption.

Before proceeding, it is useful to briefly discuss the intuition for the above results. In order to smooth consumption in the standard life-cycle model (i.e. with only nondurable consumption), households can borrow from their future income to finance current consumption. Implicit in the standard model is the use of consumer loans as a mechanism for smoothing. Household consumption, however, always behaves according to the Euler Equation which, in turn, is not affected by the repayment of the consumer loan. The same intuition applies to the current model: households smooth consumption between periods and the Euler Equation is not affected by the vehicle loan repayment.

\section{The Data}

This study uses data from the Consumer Expenditure Survey's (CEX) Interview Survey (United States Department of Labor, various years). The CEX is an on-going rotating panel dataset where consumer units (households) participating in the survey are interviewed up to five times with a space of three months between each interview. In any given calendar quarter, approximately 5,000 consumer units (CUs) are interviewed with some CUs beginning their participation in the survey and others completing their fifth (final) interview. The initial interview collects household demographic information which is updated during subsequent interviews to reflect any changes in household composition. The second through fifth interviews each collect consumer unit expenditure information for the three calendar months immediately preceding the interview. Thus, each consumer unit will have up to four quarterly observations of expenditure data. ${ }^{4}$ In addition, information on household income, referring to the twelve months prior to the interview, is collected only during the second and fifth interviews. Income data are collected for each member of the CU age 14 and above. Following the advice of the BLS staff, federal, state, and FICA (Social Security) taxes for each CU are calculated by using the NBER's TAXSIM program (Feenberg and Coutts 1993). All dollar figures are deflated to the January 2000 CPI-U

\footnotetext{
4 Note that quarterly here does not necessarily refer to calendar quarter since interviewing is performed during all twelve calendar months.
} 
using information on the interview month and year. Additional information on the CEX data used in this study including the construction of the data for use with the TAXSIM program are detailed in the Data Appendix.

The CEX also collects data on all types of vehicles including cars, trucks, motorcycles, and boats during the initial interview. A variety of data is collected for each vehicle including information on the vehicle model, the purchase date, and, if one exists, the vehicle loan. Loan information includes the date of the first payment, the number of payments contracted, and the amount of each payment. ${ }^{5}$ During the second through fifth interview, information is collected detailing whether the CU disposed of any vehicles, or if a new vehicle has been purchased. In addition, the status of each existing vehicle along with any corresponding vehicle loan is updated throughout the CU's participation in the survey.

For this study, some consumer units are deleted due to missing data. The primary reason for deleting CUs is when they are deemed by the BLS to have incomplete income data (20 percent of the sample). This designation is in general based upon the reporting of values for major sources of income such as wages and salaries, self-employment income, and Social Security income. These households are not used because the BLS sets all income data to zero (even for categories in which data is reported) for this set of CUs. ${ }^{6}$ In addition, CUs with top-coded before-tax income are deleted. Vehicles with outstanding loans that have missing or top-coded information for the vehicle purchase date, date of first payment, or monthly payment amount are excluded from the analysis. In addition, vehicles are excluded if the recorded monthly payment amount changes by more than $\$ 10$ between interviews or if the vehicle purchase date is more than six months before or one month after the first loan payment. ${ }^{7}$ Vehicles that are disposed of by the CU prior to the final loan payment are also excluded from the analysis. ${ }^{8}$ Finally, consumer

5 In the public use data, all loan payment information has been converted to a monthly frequency.

6 See United States Department of Labor (Various Years) for more details.

7 Overall, these exclusions based upon vehicle information affect eight percent of CUs with outstanding vehicle loans.

8 The robustness of the results to exclusions based upon vehicle loan data and changes in vehicle status 
units must complete at least two consecutive interviews in order to contribute at least one first-difference observation to the analysis.

Table 1 compares the characteristics of consumer units with vehicle loans, as well the subset of such consumer units with a loan expiring during the survey, to the overall sample. The information is taken from each CU's first quarterly interview from the sample of households with at least one first-difference observation. Slightly less than one-third of all consumer units have outstanding vehicle loans and one-seventh of these loans will end while the $\mathrm{CU}$ is participating in the survey. Consumer units with outstanding loans are slightly younger, have larger incomes and family sizes, and have more vehicles relative to the overall sample. As the Table indicates, total vehicle loan payments constitute roughly 12 percent of monthly after-tax income. ${ }^{9}$ The Table also reveals differences between all consumer units with loans and those whose loans expire. Total monthly payments are slightly higher while the number of payments are lower for CUs that pay off their loans. The reason for these latter discrepancies is that consumer units are more likely to keep a car until the loan is paid off if the loan is of a shorter duration. Furthermore, loans that are contracted for a shorter maturity have larger monthly payments.

\section{Empirical Methodology}

The test of the LCPIH in this paper requires a measure of the after-tax income change between two consecutive quarters due to the loan repayment. This measure is constructed in two steps. First, the reduction in quarterly vehicle payments between quarters $t$ and $t+1$ due to the repayment of a vehicle loan, $\Delta$ Payment $_{t+1}$, is calculated. Note that the change in payments will depend upon exactly when the loan ends. If the final loan payment occurs during the last month of quarter $t$, then quarterly discretionary income will be increased for all three months of quarter $t+1$ relative to quarter $t$. If the final loan payment occurs during the second month of quarter $t+1$, then quarterly income in

are examined below.

9 Median values are reported for this variable since a few outliers have extremely large, and in some cases negative, ratios. The range of this ratio is restricted in the analysis which affects less than 3 percent of CUs with ending loans. Details of this restriction are given in the Data Appendix. The results are robust to variations in the method used to impose this restriction. 
quarter $t+1$ will be higher for just one (the third) month relative to quarter $t$. If the final loan payment is made during the second month of quarter $t$, then quarterly income will be increased for one month during quarter $t$ as well as all three months of quarter $t+1$. In this case, the relative increase in quarterly income between quarters $t$ and $t+1$ will be only two months of discretionary income. Note that the $\Delta$ Payment $_{t+1}$ variable may be non-zero for a given consumer unit during more than one first-difference observation for a given vehicle. ${ }^{10}$

The second step in constructing the measure of increased quarterly income is to divide the $\Delta$ Payment $s_{t+1}$ variable by after-tax income to create the ratio

$$
\Delta P_{t+1}=\frac{-\Delta \text { Payments }_{t+1}}{\text { After-tax income }}
$$

This ratio represents the percentage increase in discretionary income between two consecutive quarters due to the loan repayment. Total vehicle payments are decreasing when the loan is paid off, so this measure has been multiplied by -1 to represent the increase in discretionary income. Since income is only reported during the second and fifth interviews, After-tax income $_{t}$ is constructed by applying the income information from the second interview to the TAXSIM program. Since After-tax income $_{t}$ remains constant for a given CU across all of its observations, all of the variation in $\Delta P_{t+1}$ for that consumer unit is due to variation in $\Delta$ Payment $_{t+1} \cdot{ }^{11}$

The empirical specification for testing whether consumption is excessively sensitive to increased discretionary income due to a loan repayment is

$$
\Delta \ln C_{i, t+1}=\alpha \Delta P_{i, t+1}+\beta \Delta X_{i, t+1}+\gamma M O N T H_{t+1}+\delta Y E A R_{t+1}+\epsilon_{i, t+1}
$$

where $\Delta \ln C_{i, t+1}$ is the change in log consumption between quarters $t$ and $t+1, \Delta X_{i, t+1}$ are controls for changing demographic characteristics (age, age squared, changes in the number

\footnotetext{
10 Suppose a consumer unit's car loan expires during the second month of period $t+1$. Then, as the above examples illustrate, the variable $\Delta$ Payment $s_{t+1}$ will be non-zero for the change between periods $t$ and $t+1$ as well as the change between periods $t+1$ and $t+2$.

11 Another result due to After-tax income $t$ remaining constant is that the variable $\Delta P_{t+1}$ is approximately equivalent to the change in log discretionary income between quarters $t$ and $t+1$.
} 
of adults and changes in the number of children), $M O N T H_{t+1}$ are calendar month effects, $Y E A R_{t+1}$ are calendar year effects, and $\epsilon_{i, t+1}$ is a household specific error term. ${ }^{12}$ The test of the LCPIH is the coefficient on the percentage increase in discretionary income, $\alpha$. The null hypothesis is that this coefficient should equal zero. Rejection of this null is considered evidence against the standard LCPIH. Equation (8) is estimated using OLS and correcting the standard errors to account for the use of multiple observations per consumer unit.

The consumption measure examined in this paper is expenditure on non-durable goods. For this study, non-durable goods are defined as food and alcohol (both at home and away from home but excluding meals received as pay), house-furnishings (excluding furniture, major appliances, and floor coverings), apparel and services, entertainment, personal care, reading, and tobacco-related items. The difference between this measure of non-durables and that previously used in the literature (e.g., the Parker and Hsieh papers) is that public transportation and gas and motor oil are excluded to avoid any contemporaneous changes in these categories that may occur when the vehicle loan expires.

The primary analysis is restricted to those first-difference observations in which $\Delta P_{i, t+1}$ is non-zero, i.e. where the loan expires during one of the two quarters. As mentioned above, a given consumer unit may contribute more than one first-difference observation depending upon when their loan expires. Thus, the impact of loan repayment on household consumption is identified both by the differential impact of the loan repayment on discretionary income across consumer units and by the differential magnitude of the impact within consumer units across quarters. The primary reason for excluding observations where $\Delta P_{i, t+1}$ is zero is the lack of an obvious control group. However, the impact of including control observations is also examined. To maximize the comparability with observations where a vehicle loan is repaid, control observations are the subset of observations with at least one vehicle loan that will be repaid in less than one year from the first month of the first-difference time period.

12 This empirical specification of the Euler Equation can be generated by assuming an isoelastic utility function for non-durable consumption and has become fairly standard in the literature. 


\section{Results}

The main empirical results from estimating equation (8) are presented in Table 2. Three sets of results are presented. The first column restricts the analysis to the primary sample, those observations in which $\Delta P_{i, t+1}$ is non-zero. The second column includes as controls observations from the quarters prior to the final loan payment from the set of households whose loans expire during their survey participation period (i.e., CUs with at least one observation with a non-zero $\left.\Delta P_{i, t+1}\right)$. The final column of the table adds all observations with at least one loan that will expire in less than one year as controls. The estimated coefficients for age and its square are statistically insignificant across all specifications in Table 2. The coefficients on the variable controlling for changes in the number of adults is statistically significant across all three columns while the impact of changes in the number of children is (marginally) significant in the last two.

The coefficients on the main regressor of interest, $\Delta P_{t+1}$, show evidence of excess sensitivity to the increased discretionary income following the repayment of a vehicle loan. In the primary sample (column 1), the coefficient on $\Delta P_{t+1}$ is statistically significant. The results imply that a 10 percent increase in after-tax income will increase non-durable consumption by 3.1 percent. When pre-loan repayment observations for the households with loans expiring are added to the sample (column 2), the coefficient of interest is still significant and only slightly smaller in magnitude. Including all observations with loans set

to expire within a year, the implied impact of 10 percent increase in discretionary income on non-durable consumption falls to 1.9 percent. Note that each of the coefficients on $\Delta P_{t+1}$ are well within the 95 percent confidence intervals for the estimates in the other columns.

One potential concern with the results in Table 2 is that they may be due, in least in part, to spurious correlation. If households whose loan payments comprise a large fraction of their after-tax income also have faster consumption growth relative to other households, then the coefficient on $\Delta P_{t+1}$ may be picking up this correlation. One might especially be concerned about a spurious relationship since younger households have relatively faster consumption growth and are also likely to have vehicle loans that comprise a larger fraction of their income. 
To examine this potential problem with the interpretation of the results in Table 2, a set of falsification tests is performed. Equation (8) is modified to allow the increase in after-tax income due to the loan repayment to affect consumption not only in the period when the loan expires, but also in the periods prior to the final loan payment. Thus, the modified equation is

$$
\begin{aligned}
\Delta \ln C_{i, t+1} & =\pi_{1} \Delta P_{i, t+1}^{*}+\pi_{2} \Delta P_{i, t+1}^{*} * \text { PAIDOFF } \\
& +\beta \Delta X_{i, t+1}+\gamma M O N T H_{t}+\delta Y E A R_{t}+\epsilon_{i, t+1}
\end{aligned}
$$

where $P A I D O F F$ is a binary indicator for whether or not a vehicle loan expired during either period $t$ or $t+1$. The estimate of $\pi_{1}$ will capture the portion of consumption growth that is spuriously related to the loan's relative share of household income. After controlling for this effect, $\pi_{2}$ measures the increase in consumption due to the the loan repayment.

Note that equation (9) uses a modified version of $\Delta P_{i, t+1}$. For observations in which the loan expires, $\Delta P_{i, t+1}^{*}$ equals $\Delta P_{i, t+1}$ as previously defined. For observations in which the loan does not expire, a measure of the increase in after-tax income if the loan were to expire in the current period is not straightforward to construct since this measure depends not only on the size of the loan but also on which month during the observation period that the loan is re-paid. The approach used here is as follows. If the household is observed with a loan expiring during the survey period, then $\Delta P_{i, t+1}^{*}$ for this household's observations prior to the loan expiration is $\Delta P_{i, t+1}$ from the first observation in which $\Delta P_{i, t+1}$ is positive. ${ }^{13}$ If the household is within the final year of its loan but does not have a loan expiring during its participation in the survey, then $\Delta P_{i, t+1}^{*}$ equals the monthly amount of each loan that will run out within the year multiplied by $1.8 .^{14}$

The results of estimating (9) are presented in Table 3. Column 1 of the Table matches column 2 of Table 2 in that only observations from households whose loans expire during

13 Recall that the depending upon when a loan expires during the survey period, the household may have more than one observation where $\Delta P_{i, t+1}$ is positive.

14 Discretionary income will increase by one months of payments if the last payment is in the first month of quarter $t$ or the second month of quarter $t+1$. The increase will be two months of payments if the final payment is in the second month of quarter $t$ or the first month of quarter $t+1$ and three months of payments if the final payment is the third month of quarter $t+1$. Assuming the loan will randomly end during any of these months, the expected increase in income is 1.8 months of payments. 
the survey are used as controls. The estimate of $\pi_{1}$ is insignificant which indicates that there is not an underlying correlation between the percentage of income committed to the vehicle loan and consumption growth. The estimated $\pi_{2}$ is significant, positive, and nearly identical to the results found in Table 2. When observations from households whose loans will expire within one year but after their participation in the survey are also included in the analysis (column 2), the results are nearly identical to the analogous result in column 3 of Table 2. These results indicate that the estimates in Table 2 are indeed due to the increase in income once the loan expires and are not spurious findings.

It is useful to interpret the results in Tables 2 and 3 in the context of other papers that have rejected the LCPIH using exogenous changes in household income. Parker finds that a 10 percent increase in after-tax income due a reduction in U.S. payroll taxes increases non-durable consumption by 5 percent. Using a framework that allows the computation of marginal propensities to consume, Souleles finds that each additional dollar of income due to an income tax refund increases a subset of non-durable consumption by 10 cents. ${ }^{15}$ Thus, the results shown here are comparable to previous findings although using a different source of variation in household income.

\section{Robustness of the Results}

Table 4 presents results of estimating (8) on a variety of sample specifications to examine the robustness of the results. The first row of the Table shows the main results found in Table 2. Concerns that excessive weight given to observations with large consumption changes may affect the parameter estimates has led some previous studies to "trim" these observations from the sample. However, recent work by Bollinger and Chandra (2003) indicates that well-intentioned trimming of the dependent variable will bias the point estimates towards zero. For purposes of comparison, row 2 of Table 4 shows the result from eliminating observations with consumption changes that exceed 100 percent. ${ }^{16}$ As expected,

\footnotetext{
15 Souleles examines a category of expenditures called strictly non-durables which is comprised of the components of non-durable consumption believed to be non-durable at a quarterly interval.

16 To treat the observations symmetrically, log consumption changes that exceeded 0.693 in absolute value where deleted.
} 
trimming the observations reduces the point estimate although it is still significant. An alternative method to control for the potential influence of outliers on the results is to use a median regression. The estimate in the third row of Table 4 using this estimation method produces an estimate that is comparable to the main result shown in row $1 .{ }^{17}$

The last three rows of Table 4 show the robustness of the results across different restrictions regarding the vehicles included in the analysis. The main results exclude vehicles that were disposed by the household prior to the vehicle's loan being completed. This restriction amounts to eliminating vehicles that the CU possesses during the first month of the first quarter of a first-difference observation but disposes prior to the loan's contracted completion date during the period covered by that observation. Row 4 of Table 4 indicates that including these vehicles in the analysis does not affect the estimates. Another restriction on the sample removes vehicles for which loan information is missing, changing, or top-coded. For vehicles that have changing or top-coded vehicle loan information, $\Delta P_{i, t+1}$ can be calculated assuming that this information is correct as it appears in the data for the quarter in question. Including these observations does not impact the results (Row 6 of Table 4). Finally, restricting the vehicles examined in the analysis to cars, trucks, and motorcycles (Row 7 of Table 4) slightly increases the estimated impact of loan repayment on non-durable consumption. In all, the various robustness checks do not change the qualitative interpretations of the main estimates.

\section{Longer-Run Effects on Consumption}

Another question of interest is whether these increases in consumption when the vehicle loan expires represent a permanent increase in consumption or reflect a one-time increase following the final loan payment. If households "reward themselves" or "splurge" after the repayment of a loan, then we may see a temporary increase in consumption following the repayment of the loan. Unfortunately, the relatively short duration of the CEX participation period limits the examination of the longer-run impacts to less than one calendar

17 The median regression standard errors are calculated as the standard deviation of the bootstrapped distribution for the parameter estimate. Each of the 200 bootstrap replication samples were constructed by re-sampling consumer units to maintain any within consumer unit correlations. 
year. On the other hand, most changes in consumption will likely occur within this time frame and examining changes over a longer horizon (e.g., annual consumption changes) increases the likelihood of falsely attributing consumption changes to the repayment of the vehicle loan.

To examine the longer run impacts on consumption, Table 5 presents the results of using the change in consumption between quarter $t$ and quarter $t+2$ as the dependent variable. This longer time frame for the dependent variable allows the analysis to focus on the before and after effects of the loan change rather than examining the immediate response to the loan repayment. As such, the regressor $\Delta P_{i, t+1}$ is replaced with the total percentage increase in quarterly income due to the loan repayment.

Column 1 of Table 5 presents the results for the impact on non-durable consumption between quarters $t$ and $t+2$ if the vehicle loan expires in quarter $t+1$. The point estimate of 0.320 is nearly identical to the main estimate found in Table 1 although the estimate is now significant at the 6 percent level. Of course, the consumption response at this interval may still reflect one-time increases in consumption. To examine the response over a longer duration, column 2 of the Table examines the response to loans that expire during period $t .^{18}$ Again, the point estimate is nearly identical to the previous result. Overall, these results suggest that the increase in consumption upon repaying a vehicle loan is a longer-run rather than only a short-run response.

\section{The Role of Liquidity Constraints}

Since the influential paper by Zeldes (1989), a finding that consumption exhibits excess sensitivity to predictable income changes is explored to see if liquidity (borrowing) constraints can explain such a result. The methodology typically used is to split the sample into two sets of households - those likely to be borrowing constrained and those who likely are not - using a measure of household wealth to implement the sample split. As discussed

18 Although the regressor used in Column 2 is based upon an entire quarter's increase in income, the increase in discretionary income in period $t$ will depend upon when the loan expires during this period. In fact, the actual increase in income between periods $t$ and $t+2$ may be less than the total increase in quarterly income. Therefore, the estimate in Column 2 may understate the true consumption response. 
in section 2, constrained households are expected to violate the standard Euler equation. However, unconstrained households should not violate the traditional null hypothesis.

Before continuing, it is an interesting question to ask whether households that have vehicle loans can be considered borrowing constrained. In the sense of having any access to capital markets, the answer must be that they are not constrained since they do in fact have a loan. However, this loan is one that uses the vehicle as collateral. The potential loss to lenders due to a household's inability to repay such a loan can be minimized by repossessing the vehicle. A non-collateralized loan, e.g. a consumer loan, is the type that underlies the standard life-cycle model. Consumers may have difficulty obtaining these loans to increase current non-durable consumption. As such, households with vehicle loans may be considered borrowing constrained with regards to debt that cannot be collateralized.

The analysis here proceeds along the same lines as prior studies but uses three methods to split the sample: age of the consumer unit, liquid wealth of the consumer unit, and the maturity (number of payments) of the expiring loan. Each of these splits proxies for the presence of borrowing constraints. Younger households have, relative to older households, steeper earnings profiles which increases the likelihood that they are currently borrowing constrained. Households with less liquid wealth may have less access to capital markets than wealthier households. Households with a longer loan maturity are more likely to be borrowing constrained than those with a shorter maturity. Attanasio, Goldberg, and Kyriazidou (2000) show in their model that constrained households can purchase more expensive vehicles by simply increasing the number of payments while holding the amount of each payment constant. Thus, one would expect loans with longer maturities to be more prevalent among constrained households.

Table 6 presents the results of the borrowing constraint analysis. The top panel of the Table divides consumer units into those below the sample median age and those above the median age. ${ }^{19}$ The consumption response is large and significant for the younger households; a 10 percent increase in discretionary income yields a 5 percent increase in non-durable consumption. For the households above the median age, the consumption

19 The median age in the sample is 41. Gourinchas and Parker (2002) estimate that households switch from buffer-stock behavior to standard life-cycle consumers around the age of 40 . 
response is small and insignificant. Note, however, that the relatively large standard errors for the point estimates cannot reject the null hypothesis that the effects are the same for both age groups. ${ }^{20}$

The middle panel of Table 6 splits the sample based upon the consumer unit's place in the liquid wealth-to-income distribution. Liquid wealth is calculated as the sum of the balances in the consumer unit's checking and savings accounts. Wealth information is only asked during the fifth interview and thus is only available for households that do not leave the sample prior to their final interview. Furthermore, a number of households have missing data for wealth information. The combination of these two restrictions yields wealth information for roughly two-thirds of the observations. Liquid wealth is then normalized by the household's annual after-tax income. Household's with a liquid wealth-to-income ratio less than or equal to 0.012 (approximately the first, or lowest, quartile) are those most likely to be borrowing constrained. Those households with a ratio of 0.192 or greater (approximately the highest quartile) are used as a comparison group. The point estimate for the low wealth ratio consumer units is relatively large but insignificant. The estimate for the high wealth ratio CUs is smaller than the full sample estimates and insignificant. Even given the magnitude of the difference between the estimates for the two groups, the difference is not statistically significant.

The final sample split is based on loan maturity. As discussed above, loans that are longer in duration are more likely to be taken by constrained households. As can be seen in Table 1, the average loan maturity among consumer units with loans that end is 36 monthly payments. The sample is divided between those with maturities of not more than 36 months (roughly 60 percent of the observations) and those whose maturity exceeds 36 months. The bottom panel of Table 6 shows that the estimates do not differ greatly between these two sets of households. The impact on consumption is only slightly greater for the longer maturity households and the estimates for both groups of households are (marginally) statistically significant. Hence, using maturity as a proxy for borrowing constraints cannot explain the results found in this study. One reason for the inability to

\footnotetext{
20 Although not reported here, pooled regressions allowing for a direct test of the difference in the response between the two groups cannot reject the null hypothesis.
} 
find a differential response by loan maturity is that maturity length reflects the presence of borrowing constraints at the time the vehicle is purchased but may not be a strong indicator of these constraints upon the repayment of the loan. Nevertheless, the results when the sample is divided either by age or by wealth are suggestive of a role for borrowing constraints in explaining the findings.

\section{The Response Across Consumption Categories}

The final question examined in this paper is whether the consumption response to the final vehicle loan payment varies across the category of expenditure. Parker (1999) discusses a bounded rationality scenario in which consumption goods with higher intertemporal elastiticies of substitution are more likely to vary with changes in income since the utility loss from delaying consumption of these goods is relatively small. Using a more conventional framework, Browning and Crossley (2000) prove that luxury goods have a higher intertemporal elasticity of substitution and are thus "easier to postpone". Therefore, one would expect to find a heterogeneous response across consumption categories with larger responses for luxury goods.

Table 7 presents the results of estimating equation (8) across sub-categories of nondurable consumption. For ease of comparability, the first row of the Table presents the result for non-durable consumption from Table 2. Food and alcohol consumption generates a relatively small and insignificant response to loan repayment. Entertainment and personal care expenditures exhibit a marginally significant response that exceeds the overall non-durable consumption response in magnitude. ${ }^{21}$ Apparel expenditures also show a larger response than total non-durable consumption although the point estimate is insignificant. Overall, the results in Table 7 are consistent with the hypothesis that luxury goods are more likely to be substituted intertemporally.

\footnotetext{
21 Entertainment and personal care includes reading and tobacco along with personal care consumption
} and entertainment expenditures which include fees, admissions, televisions, radios, and sound equipment. 


\section{Conclusion}

This paper examines whether household consumption is excessively sensitive to predictable changes in discretionary income due to the repayment of a vehicle loan. The date and amount of a final vehicle loan payment are known to the household for a substantial length of time before it occurs. Under the Life-Cycle/Permanent Income Hypothesis, consumption should not be excessively sensitive to the increase in discretionary income caused by paying off a vehicle loan. The results presented here are evidence against this implication of the LCPIH. A 10 percent increase in discretionary income due to the final repayment of a vehicle loan increases non-durable consumption by 2 to 3.5 percent. The results are robust to a number of sample specifications. The presence of liquidity constraints can explain the findings when age and wealth are used as proxies for these constraints while using the loan's maturity as a proxy cannot. Finally, the non-durable items that are more likely to be luxury goods and have higher intertemporal substitution elasticities exhibit the largest response.

The current study adds to the small but growing set of papers that examine the consumption response to exogenous income changes. The studies in this literature tend to find that households "smooth" consumption in response to predictable seasonal income fluctuations while there is excess sensitivity to less frequent, but expected income changes. Browning and Crossley (2002) suggest that these differential findings are consistent with households "getting it right" when the utility losses from not doing so are large. In the case of vehicle loans considered in this paper, notice that the results imply that household consumption is lower throughout the entire duration of the loan which, at the sample median, is 36 months (among loans that expire before the household disposes of the vehicle). On the one hand, this relatively long period of time with less than optimal consumption suggests that the utility losses implied by the results here may be large. On the other hand, the final set of results in Table 6 suggests that most of this behavior can be explained by borrowing constraints in which case the welfare losses are due to capital market imperfections and not non-optimal behavior on the part of consumers. 


\section{Data Appendix}

The data for this study are taken from the 1984-2000 Consumer Expenditure Surveys. Consumption information is calculated from the detailed expenditure files. The expenditure data are summarized such that the month and year of purchase matches the three month period covered by the quarterly interview. A small fraction of expenditures are dated outside of the interview period. Following previous studies, these expenditures are moved to the interview quarter that covers the date of purchase. Expenditure data are deflated to the January 2000 CPI-U using the monthly CPI-U corresponding to the interview month and year.

The primary regressor of interest, $\Delta P_{t+1}$, has some extremely large outlier values since it is the ratio of the change in quarterly payments to the consumer's unit after-tax income. These outliers are removed from the analysis using the following procedure. First, the household's ratio of the monthly vehicle payments to after-tax income is constructed. This ratio is considered to be an outlier if it is less than zero (which can occur if the CU reports large business losses) or exceeds 0.50. For outlier observations, $\Delta P_{t+1}$ is set to its actual value if it lies between zero and $0.50 .^{22}$ The remaining outlier observations are removed from the analysis. The results are robust to other methods of treating outlier values for this regressor.

Federal, state, and FICA taxes for each consumer unit are calculated using NBER's TAXSIM program. Although consumer units may not correspond to taxpaying units, for the purposes of this paper consumer units are considered to be the taxpaying unit. This assignment is necessary since a) only relationships to the reference person are known and not relationships among other $\mathrm{CU}$ members and b) some income information such as interest, dividends, and welfare, unemployment, and worker's compensation payments are collected for the consumer unit as a whole.

The consumer unit is considered to be married if the reference person is coded as married (the variable MARITAL1 $=1$ ).${ }^{23}$ For married households, the number of depen-

\footnotetext{
22 Remember that $\Delta P_{t+1}$ can differ from the monthly payment ratio since the former is calculated at a quarterly frequency and depends upon the month during the quarter when the loan expires.

23

All variables are taken from the CEX family files unless otherwise noted.
} 
dents equals the number of members of the consumer unit (FAM_SIZE) minus two. ${ }^{24}$ For all other consumer units, the number of dependents equals the family size minus one. ${ }^{25}$ Among the non-married households, if there are no dependents present, then the CU's tax status is single. If dependents exist in these CUs, the CU's tax status is head of household. Age exemptions (ages 65 and up) are based on the age of the reference person and their spouse.

The various components of CEX consumer unit income are used to construct the income data necessary for the TAXSIM program. The taxpayer's income and the income of the taxpayer's spouse are taken from the CEX member files (SALARYX). In married households, the male is considered the taxpayer for consistency purposes. Dividend income is taken from the variable FININCX. Other property income is the sum of the variables INTEARNX, INCLOSSA, INCLOSSB, ALIOTHX, OTHRINCX, and EARNINCX minus the sum of SALARYX among the taxpayer and their spouse. Taxable pension income is taken from PENSIONX while gross Social Security income is from FRRETIRX. Other nontaxable transfer income is the sum of FSSIX, COMPENSX, WELFAREX, CHDOTHX, and JFDSTMPA. ${ }^{26}$ Unemployment compensation is taken from the variable UNEMPLX.

State taxes are calculated based on the CU's state of residence at the time of their first available survey. Note, however, that for confidentiality reasons, state and/or region of residence are masked for some CU's (approximately 20 percent). If state of residence is unavailable but region of residence is available, then the CU's state tax is the average of the state tax they would pay in each of the states in their region. If both the state and region of residence are unavailable, then the CU's state tax is the average of the state tax they would pay in every state in the United States. Beginning in 1996, masking of state of residence is performed by recoding some values to the values of other states. If the CU's state has been recoded or if the CU lives in a state to which other values are recoded (in

\footnotetext{
24 In the few cases where a one person consumer unit is married, the number of dependents is set to zero but the consumer unit is still identified as married for tax purposes.

25 The number of dependents is capped at fifteen which affects one consumer unit.

26 Since the CEX includes the value of food stamps (JFDSTMPA) in total before-tax income, these benefits are included in non-taxable transfer income.
} 
both cases STATE_$\left._{-}=\mathrm{R}\right)$, then the CU's state tax is the average of the state tax they would pay in every state in the United States. 


\section{Bibliography}

Alessie, Rob, Michael P. Devereux, and Guglielmo Weber (1997) "Intertemporal Consumption, Durables and Liquidity Constraints: A Cohort Analysis," European Economic Review, 41, X, 37-59.

Altonji, Joseph G. and Aloysius Siow (1987) "Testing the Response of Consumption to Income Changes With (Noisy) Panel Data," Quarterly Journal of Economics, 102, 2, $293-328$.

Attanasio, Orazio (1995) "Consumer Durables and Inertial Behavior: Estimation and Aggregation of (S,s) Rules," National Bureau of Economic Research Working Paper \#5282.

Attanasio, Orazio, Pinelopi K. Goldberg, and Ekaterini Kyriazidou (2000) "Credit Constraints in the Market for Consumer Durables: Evidence from Micro Data on Car Loans," National Bureau of Economic Research Working Paper No. 7694.

Bollinger, Christopher R. and Amitabh Chandra (2003) "Iatrogenic Specification Error: A Cautionary Tale of Cleaning Data," National Bureau of Economic Research Technical Working Paper \#289.

Browning, Martin and M. Dolores Collado (2001) "The Response of Expenditures to Anticipated Changes: Panel Data Estimates," American Economic Review, 91, 3, 681-92.

Browning, Martin and Thomas F. Crossley (2000) "Luxuries Are Easier to Postpone: A Proof," Journal of Political Economy, 108, 5, 1022-1026.

Browning, Martin and Thomas F. Crossley (2001) "The Life-Cycle Model of Consumption and Saving," Journal of Economic Perspectives, 15, 3, 3-22.

Browning, Martin and Annamaria Lusardi (1996) "Household Saving: Micro Theories and Micro Facts," Journal of Economic Literature, 34, 4, 1797-1855.

Chah, Eun Young, Valerie A. Ramey, and Ross M. Starr (1995) "Liquidity Constraints and Intertemporal Consumer Optimization: Theory and Evidence from Durable Goods," Journal of Money, Credit, and Banking, 27, 1, 272-287. 
Eberly, Janice C. (1994) “Adjustment of Consumers' Durables Stocks: Evidence from Automobile Purchases," Journal of Political Economy, 102, 3, 403-36.

Engelhardt, Gary V. (1996) "Consumption, Down Payments, and Liquidity Constraints," Journal of Money, Credit, and Banking, 28, 2, 255-271.

Feenberg, Daniel and Elisabeth Coutts (1993) "An Introduction to the TAXSIM Model," Journal of Policy Analysis and Management, 12, 1, 189-94.

Gourinchas, Pierre-Olivier and Jonathan A. Parker (2002) "Consumption Over the Life Cycle," Econometrica, 70, 1, 47-89.

Parker, Jonathan A. (1999) "The Reaction of Household Consumption to Predictable Changes in Social Security Taxes," American Economic Review, 89, 4, 959-73.

Shapiro, Matthew D. (1984) "The Permanent Income Hypothesis and the Real Interest Rate," Economic Letters, 14, 1, 93-100.

Shea, John (1995) "Union Contracts and the Life-Cycle/Permanent-Income Hypothesis," American Economic Review, 85, 1, 186-200.

Souleles, Nicholas S. (1999) "The Response of Household Consumption to Income Tax Refunds," American Economic Review, 89, 4, 947-58.

Souleles, Nicholas S. (2000) "College Tuition and Household Savings and Consumption," Journal of Public Economics, 77, 2, 185-207.

U.S. Dept. of Labor, Bureau of Labor Statistics. CONSUMER EXPENDITURE SURVEY, INTERVIEW SURVEY [Computer file]. ICPSR version. Washington, DC: U.S. Dept. of Labor, Bureau of Labor Statistics [producer]. Ann Arbor, MI: Inter-university Consortium for Political and Social Research [distributor]. Various years.

Zeldes, Stephen P. (1989) "Consumption and Liquidity Constraints: An Empirical Investigation," Journal of Political Economy, 97, 2, 305-46. 


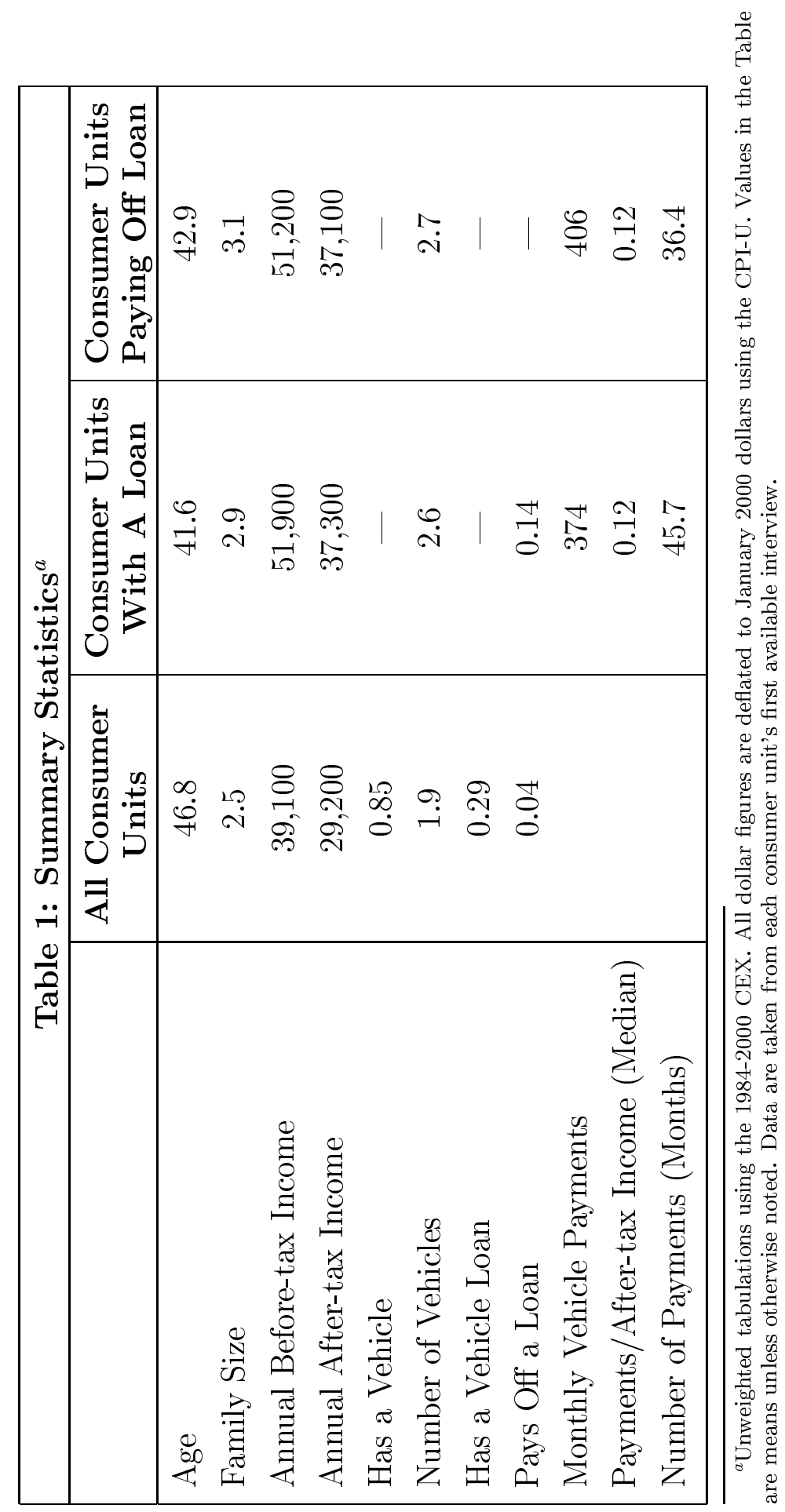




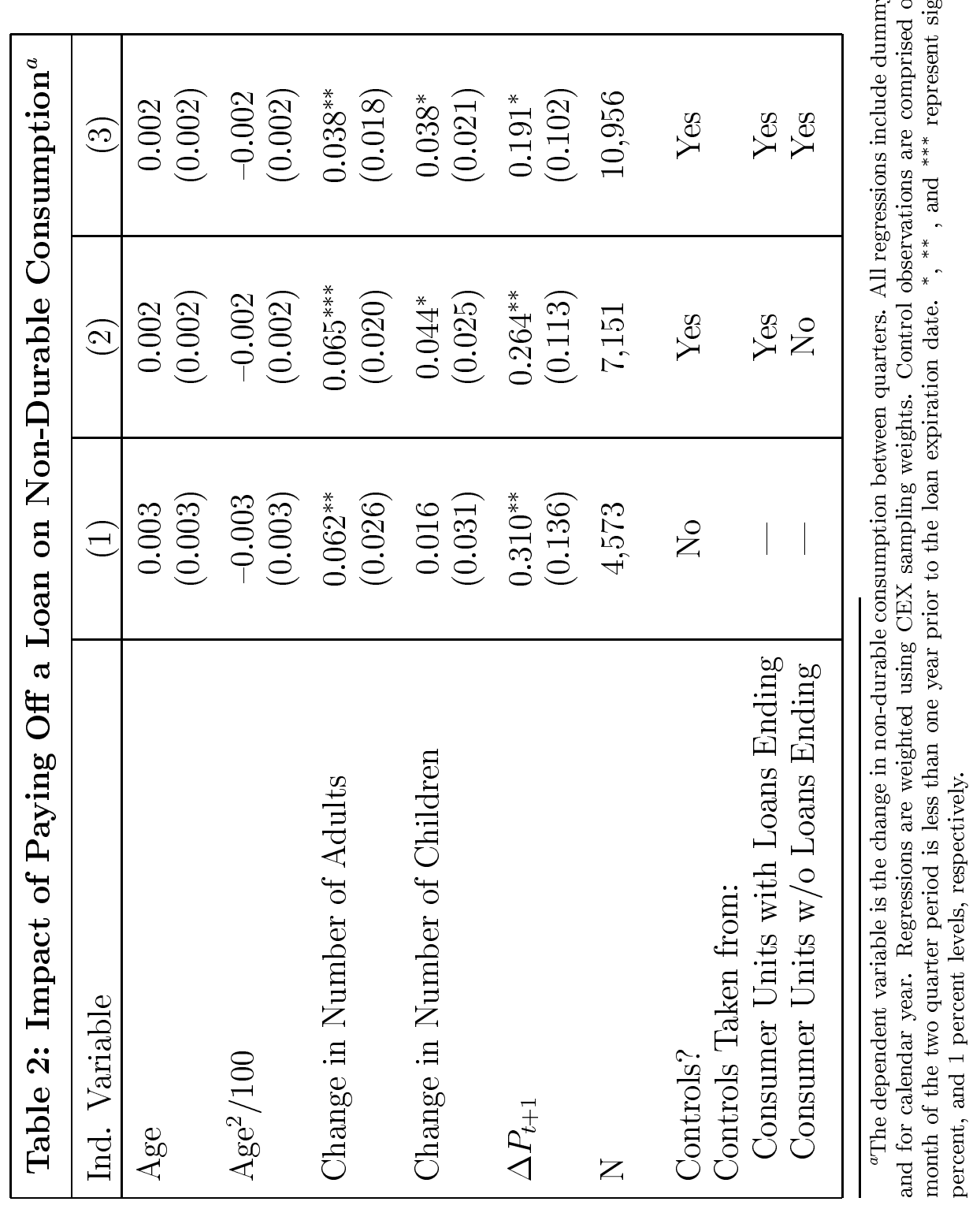




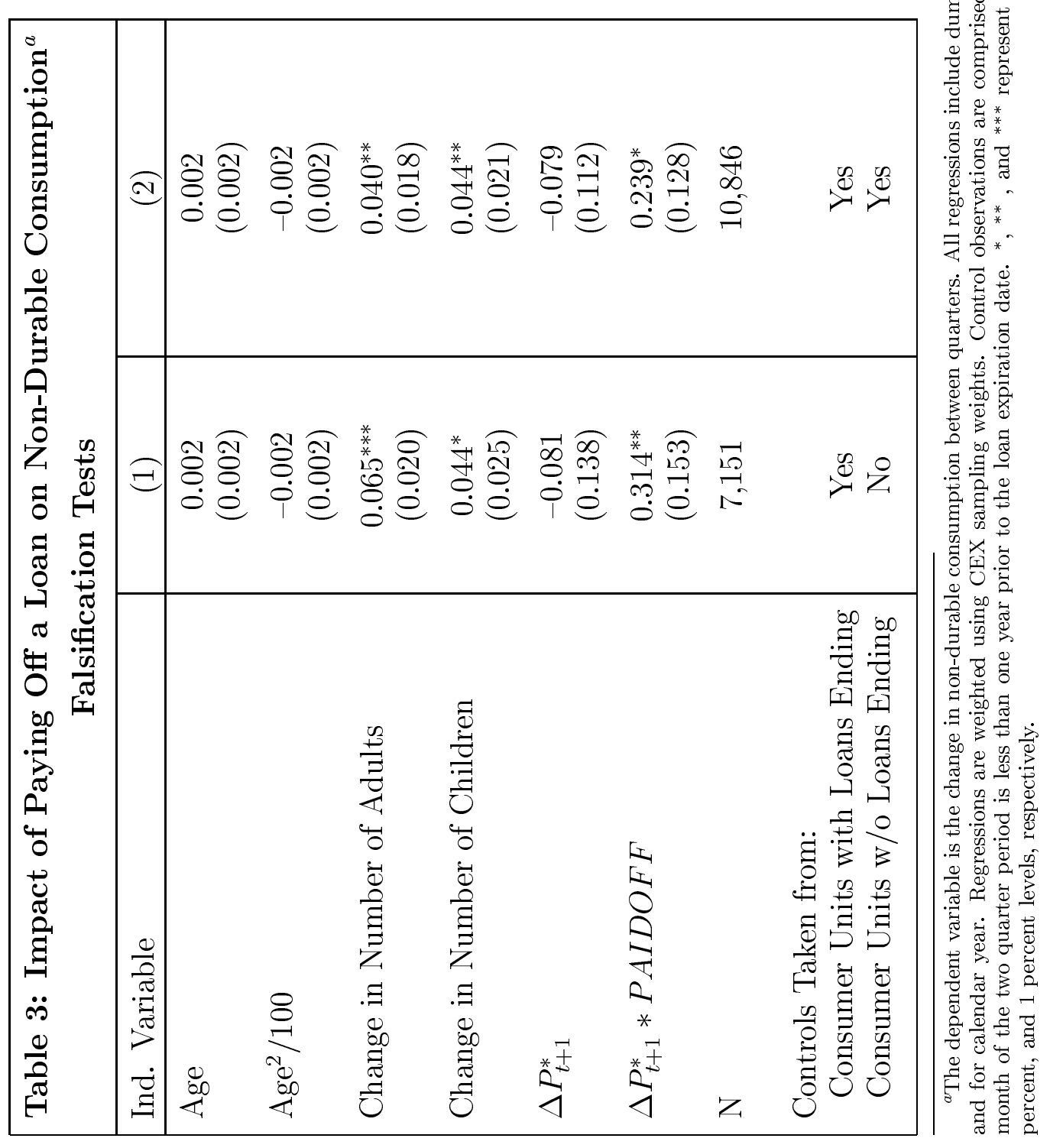




\begin{tabular}{|l|c|}
\hline \multicolumn{2}{|c|}{ Table 4: Robustness of Results ${ }^{a}$} \\
\hline Primary Sample (Table 2, Column 1) & $0.310^{* *}$ \\
N & $0.136)$ \\
Remove Outliers & 4,573 \\
& $0.208^{* *}$ \\
N & $(0.102)$ \\
Median Regression & 4,027 \\
& $0.266^{*}$ \\
N & $(0.152)$ \\
Include Vehicles Disposed Early & 4,573 \\
N & $0.333^{* *}$ \\
Include Vehicles With & $(0.135)$ \\
Incomplete Loan Information & 4,740 \\
N & $0.306^{* *}$ \\
Only Car, Truck, & $(0.132)$ \\
and Motorcycle Loans & 5,022 \\
N & $0.368^{* * *}$ \\
\hline
\end{tabular}

\footnotetext{
${ }^{a}$ The sample is comprised of all observations during which the loan ends. The dependent variable is the change in non-durable consumption between quarters. All regressions include age, age squared, changes in the number of adults and children, as well as dummy variables for calendar month and for calendar year. Regressions are weighted using CEX sampling weights. Standard errors for the median regression are calculated by using 200 bootstrap replications where each sample replication is constructed by re-sampling consumer units. ${ }^{*},{ }^{* *}$, and ${ }^{* * *}$ represent significance at the 10 percent, 5 percent, and 1 percent levels, respectively.
} 


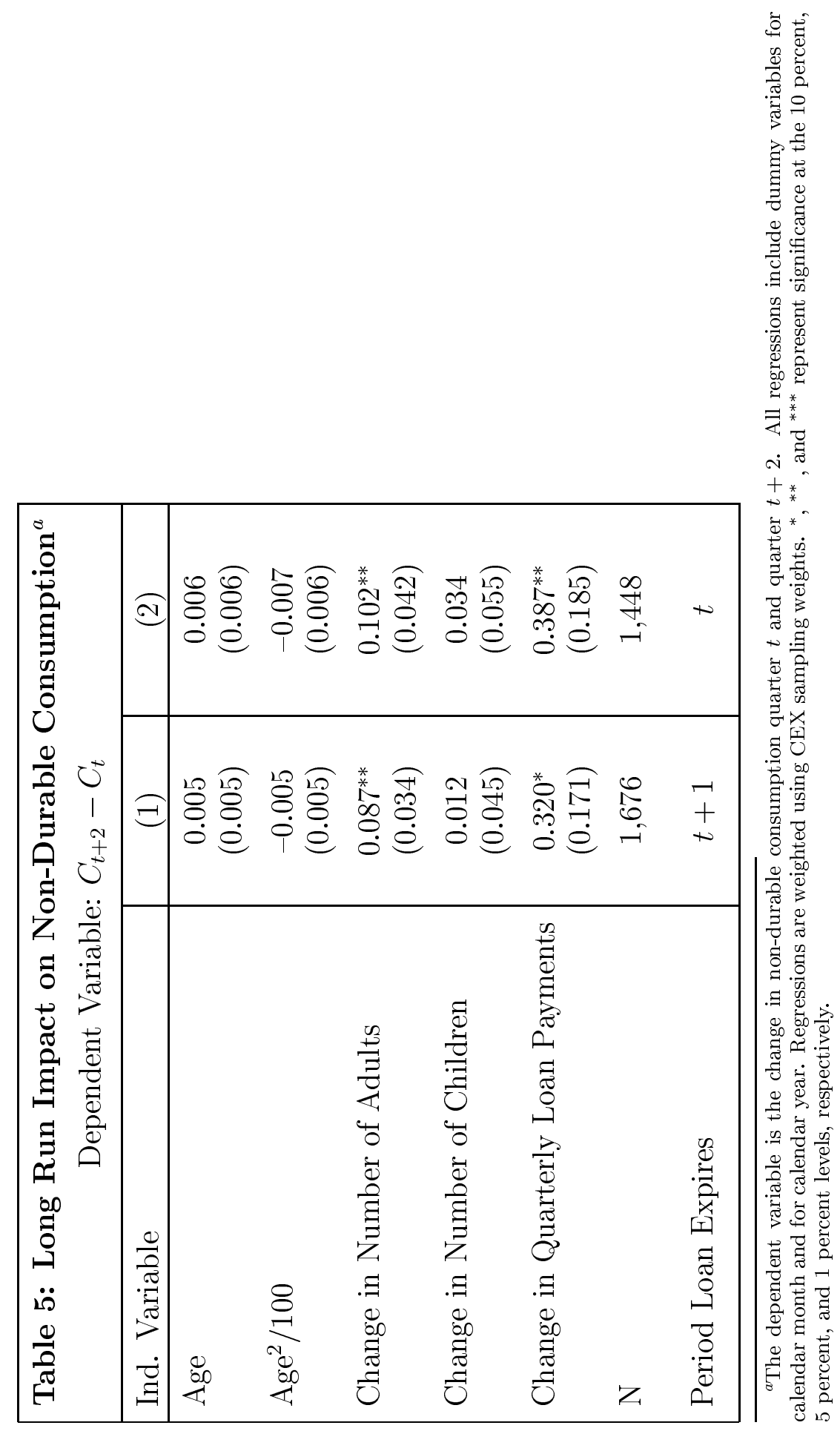




\begin{tabular}{|l|c|}
\hline \multicolumn{2}{|l|}{ Table 6: The Impact of Borrowing Constraints ${ }^{a}$} \\
\hline Less than the Median Age & $0.494^{* *}$ \\
N & $0.194)$ \\
Greater than the Median Age & 2,345 \\
N & 0.095 \\
& $(0.193)$ \\
Low Wealth Ratio (First Quartile) & 2,225 \\
N & 0.456 \\
High Wealth Ratio (Fourth Quartile) & $0.321)$ \\
N & 834 \\
Low Maturity (<=36 Months) & 0.067 \\
N & $84245)$ \\
High Maturity (>36 Months) & $0.306^{*}$ \\
N & 2,799 \\
\hline
\end{tabular}

${ }^{a}$ The dependent variable is the change in non-durable consumption between quarters. All regressions include age, age squared, changes in the number of adults and children, as well as dummy variables for calendar month and for calendar year. Regressions are weighted using CEX sampling weights. ${ }^{*},{ }^{* *}$, and ${ }^{* * *}$ represent significance at the 10 percent, 5 percent, and 1 percent levels, respectively. 


\begin{tabular}{|l|c|}
\hline \multicolumn{2}{|c|}{ Table 7: Response by Consumption Category } \\
\end{tabular}

${ }^{a}$ The dependent variable is the change in consumption in each category. All regressions include age, age squared, changes in the number of adults and children, as well as dummy variables for calendar month and for calendar year. Regressions are weighted using CEX sampling weights. ${ }^{*},{ }^{* *}$, and ${ }^{* * *}$ represent significance at the 10 percent, 5 percent, and 1 percent levels, respectively. 